\title{
POLIITICA NACIONAL DE ALFABETIZAÇÃO: O FOCO NA LITERACIA E O SILENCIAMENTO DO LETRAMENTO
}

\author{
Jânio Nunes dos Santos ${ }^{1}$ \\ Adriana Cavalcanti dos Santos ${ }^{2}$ \\ Viviane Caline de Souza Pinheiro
}

RESUMO: O artigo se materializa no intercruzamento dos discursos que integram a Política Nacional de Alfabetização e mobiliza o entendimento dos rompimentos, da referida política, com as contribuições das pesquisas nacionais sobre a especificidade da alfabetização e do letramento no Brasil. Para isso, realizamos um estudo documental do caderno da Política Nacional de alfabetização cujo corpus foi analisado com base na técnica de análise de conteúdo em Bardin (2009) e discutido a partir de Morais (2005, 2012; 2019; 2019a), Soares (2003; 2014; 2016), Bakhtin (2003; 2019), Mortatti (2006), Orlandi (2007). Os resultados demonstram reducionismos conceituais e metodológicos sobre o processo de alfabetização, que reforçam evidências científicas sobre método fônico, e, por meio da alusão às práticas de literacia, impõem o silenciamento do termo letramento, desconsiderando pesquisas consolidadas sobre alfabetização e letramento há mais de 20 anos no país.

PALAVRAS-CHAVE: Política Nacional de Alfabetização. Letramento. Literacia.

\section{INTRODUÇÃO}

A educação brasileira, no século XXI, tem gestado diretrizes e políticas que visam direcionar o processo de ensino e aprendizagem da leitura e da escrita em caráter governamental (BRASIL, 2013; BRASIL, 2018; BRASIL, 2019). Essas políticas emergem, geralmente, a partir dos resultados das avaliações diagnósticas de larga escala de caráter nacional, a exemplo da Avaliação Nacional de Alfabetização (ANA), aplicada aos alunos do ciclo de alfabetização, e do Sistema de Avaliação da Educação Básica (Saeb), que avalia a educação básica; e internacional, como os dados mensurados pelo Programa Internacional de Avaliação de Estudantes (PISA), que propõe um estudo comparativo internacional, realizado a cada três anos pela Organização para a Cooperação e Desenvolvimento Econômico (OCDE), e oferece informações sobre o desempenho dos estudantes na faixa etária dos 15 anos. Em ambas avaliações, a situação brasileira não é confortável em termos de aprendizagem, sobretudo de leitura e escrita.

Em se tratando do processo de alfabetização de crianças em idade escolar, além da Política Nacional de Alfabetização - PNA (BRASIL, 2019), outros dois documentos normativos mais recentes da educação brasileira têm implicado, a priori, em redirecionar as práticas de alfabetização e, a posteriori, as avaliações em larga escala. Esses documentos são: Plano Na-

1 Instituição: Universidade Federal de Alagoas, Orcid: https://orcid.org/0000-0003-2385-1986, E-mail: jnio.nunes@gmail.com 2 Instituição: Universidade Federal de Alagoas, Orcid: https://orcid.org/0000-0002-4556-282X, E-mail: adricavalcanty@hotmail.com 3 Instituição: Universidade Federal de Alagoas, Orcid: https://orcid.org/0000-0001-9762-5418, E-mail: viviane.cs.pinheiro@gmail.com 
cional de Educação - PNE (BRASIL, 2014) e Base Nacional Comum Curricular - BNCC (BRASIL, 2017). No entanto, por sua natureza complexa, essas políticas desconsideram os princípios da formação humana, sobretudo a última, por não colocar em evidência os usos sociais na aprendizagem da língua escrita.

O PNE (BRASIL, 2014), com duração de uma década, define na Meta 5 "alfabetizar todas as crianças, no máximo, até o final do $3^{\circ}$ ano do ensino fundamental" (p. 85); e como extensão dessa, estabelece como Meta 9 "elevar a taxa de alfabetização da população com 15 anos ou mais para 93,5\% até 2015 e, até o final da vigência deste PNE, erradicar o analfabetismo absoluto e reduzir em 50\% a taxa de analfabetismo funcional" (p. 159).

A BNCC, por sua vez, reduz a duração do Ciclo de Alfabetização para dois anos, indo de encontro ao proposto na referida Meta 5, pois "embora, desde que nasce e na Educação Infantil, a criança esteja cercada e participe de diferentes práticas letradas, é nos anos iniciais ( $1^{\circ}$ e $2^{\circ}$ anos) do Ensino Fundamental que se espera que ela se alfabetize" (BRASIL, 2017, p. 89). Conquanto apresente contrariedade com relação à duração do ciclo de alfabetização inicialmente proposto pelo PNE, a BNCC mantém o discurso em defesa do letramento (SOARES, 2014), termo que se consolidou no Brasil ${ }^{4}$ para referenciar as práticas sociais de uso da língua, sobretudo escrita.

No que se refere à PNA, embora cite as Metas 5 e 9 do PNE, recomenda a alfabetização das crianças no $1^{\circ}$ ano do ensino fundamental, reduzindo o ciclo de alfabetização e dando margem às contestações sobre a unidade no discurso dos documentos oficiais (BRASIL, 2014 ; 2017) acerca da alfabetização na "idade certa". Os reducionismos conceituais e metodológicos se agravam quando a referida política "silencia"5 o termo letramento (SOARES, 2014) do discurso oficial sobre alfabetização no Brasil, impondo em seu lugar o termo litera$c i a^{6}$ (MORAIS, 2014), o qual não configura sinônimo do termo letramento por duas questões: desconsiderar os aspectos sociais de uso da língua; e traduzir-se como conjunto de conhecimentos, habilidades e atitudes relacionados à leitura e à escrita, assim como a sua prática produtiva (entenda-se prática produtiva como codificação da língua em palavras e pequenos textos, conforme exposto na PNA).

E sobre essa questão - letramento/literacia - que objetivamos, neste artigo, refletir acerca dos discursos que integram a Política Nacional de Alfabetização (Brasil, 2019) e mobilizam os rompimentos com as contribuições das pesquisas e práticas sobre alfabetização no Brasil, além dos reducionismos conceituais e metodológicos para o silenciamento (ORLANDI, 2007) do conceito letramento. Essa discussão se reveste de importância por abordar um pro-

\footnotetext{
4 Defendemos o Letramento como termo brasileiro por ter sido inaugurado no Brasil na década de 1980 sendo que "[...] uma das primeiras ocorrências está em livro de Mary Kato, de 1986 (No mundo da escrita: uma perspectiva psicolinguística, Editora Ática) [...] Dois anos mais tarde, em livro de 1988 (Adultos não alfabetizados: o avesso do avesso, Editora Pontes), Leda Verdiani Tfouni, distingue alfabetização de letramento: talvez seja esse o momento em que letramento ganha estatuto de termo técnico no léxico dos campos da Educação e das Ciências Linguísticas. Desde então, a palavra torna-se cada vez mais frequente no discurso escrito e falado de especialistas, de tal forma que, em 1995, já figurava em título de livro organizado por Ângela Kleiman: Os significados do letramento: uma nova perspectiva sobre a prática social da escrita (SOARES, 2014, p. 15).

5 Apoiamo-nos em Orlandi (2007, p. 29) ao definir silenciamento como "toda questão do 'tomar' a palavra, 'tirar' a palavra, obrigar a dizer, fazer calar, silenciar etc" como ação intencional e não neutra.

6 Embora o termo literacia derive do termo anglo-saxônico, literacy, de extenso uso nos países de língua inglesa e até em Portugal, mas não consolidado no Brasil, não configura tradução do termo letramento, tampouco nomeia o mesmo processo (uso social da língua escrita). Optamos por utilizar o termo literacia em itálico para marcar nossa posição discursiva a respeito da não representatividade desse termo no que diz respeito ao conceito de letramento que defendemos
} 
blema atual que requer reflexão e posicionamento da academia a fim de suscitar discussões em que pese a pouca produção acadêmica, tendo destaque à Edição 10 da Revista Brasileira de Alfabetização (ABALF) publicada em 2019, que reuniu ensaios de pesquisadores brasileiros a respeito dos limites e controvérsias presentes na PNA.

Assim, realizamos uma análise de caráter documental (CELLARD, 2008), a partir da técnica da análise de conteúdo (BARDIN, 2009), sobre o documento oficial da PNA, considerando a análise de conteúdo como método de investigação substancialmente simbólico dos discursos oficiais para compreender, na política em questão, os discursos acerca de alfabetização, literacia e o apagamento do termo letramento, os quais compõem as categorias de análise. A discussão fundamentou-se em Morais (2005, 2012; 2019; 2019a), Soares (2003; 2014; 2016), Bakhtin (2003; 2019), Mortatti (2006), Orlandi (2007), entre outros.

O presente artigo divide-se em duas seções. Na primeira seção, propomos uma discussão sobre aspectos gerais da PNA que refletem reducionismos para a alfabetização no Brasil, tendo em vista o que a referida política elenca como evidências científicas na tentativa de legitimar o método fônico no processo de aprendizagem da língua escrita. Na segunda seção, abordamos o conceito de literacia. Por fim, lançamos mãos das considerações finais.

\section{ASPECTOS GERAIS E CONTROVERSOS SOBRE A POLÍTICA NACIONAL DE ALFABETIZAÇÃO}

O cenário educacional brasileiro da atualidade fez emergir novas diretrizes e políticas para se pensar e redirecionar os processos de alfabetização de crianças em idade escolar, historicamente marcado pelo fracasso do ensino-aprendizagem da leitura e da escrita (MORTATTI, 2006) na escola. Essas diretrizes e políticas (PNE, BNCC, PNA) apontam para concepções ou métodos de alfabetização, que por sua vez direcionam encaminhamentos didáticos e concepções de currículo (SANTOS; PINHEIRO; SANTOS, 2020).

Com foco na alfabetização alicerçada nos vieses fonológicos como paradigma para a aprendizagem inicial da língua escrita, a Política Nacional de Alfabetização (BRASIL, 2019) é lançada, pelo Decreto n 9.765, em abril de 2019, "sugerindo" o ensino da leitura e da escrita pelo método fônico, antecipando o que seria implementado na educação infantil e no ciclo de alfabetização, a partir do que defende como evidências científicas exitosas nacionais e internacionais.

A implementação da PNA tomou corpo com a renovação do quadro de ministro e dirigentes do Ministério de Educação e Cultura (MEC) nos cem primeiros dias do Governo Bolsonaro e ao longo do ano 2019 (com ênfase dada aos meses de abril - lançamento da proposta da PNA via decreto; e de agosto - apresentação do caderno da PNA, com texto na íntegra). A referida equipe técnica responsável pela elaboração da PNA defende a abordagem fônica no processo de alfabetização, a despeito do construtivismo que é tido, a partir de então, pelo discurso oficial como vilão da alfabetização. Assim, na PNA, com relação à ciência cognitiva da leitura, afirma-se que

[...] ao contrário do que supõem certas teorias, a aprendizagem da leitura e da escrita não é natural nem espontânea. Não se aprende a ler como se aprende a falar. A leitura e a escrita precisam ser ensinadas de modo explícito e sistemático (BRASIL, 2019, p. 20 - grifo nosso). 
Vale ressaltar que a alfabetização das crianças no Brasil não seguiu tão somente a orientação da Teoria de Aprendizagem Construtivista, que o documento nomeia de 'certas teorias', pois, para além dela, recomendava-se o desenvolvimento/aprimoramento da consciência fonológica dos escolares em fase da alfabetização. A exemplo disso, tem-se o Pacto Nacional pela Alfabetização na Idade Certa - PNAIC (BRASIL, 2013), programa de dimensão nacional que vigorou entre os anos de 2013 a 2018. O referido pacto propunha o trabalho de alfabetização com vistas ao letramento, para que o aluno compreenda o Sistema de Escrita Alfabética- SEA (MORAES, 2012), sobre ele reflita, e aprimore as reflexões que faz, sobre a língua oral mesmo antes de entrar no processo de alfabetização.

A respeito da importância de abordar a consciência fonológica, Liberman apud Soares (2016), esclarece que a língua escrita é em parte descoberta, em parte invenção, o que justifica a simbiose de métodos de alfabetização ou mesmo das abordagens psicogenética e fonológica. Segundo Soares,

Pode-se dizer que, de certa forma, a criança repete descoberta e invenção: para apro-
priar-se da leitura e da escrita em um sistema alfabético, ela refaz a descoberta de
que a palavra é uma cadeia sonora independente de seu significado e passível de ser
segmentada em pequenas unidades, tornando-se consciente da estrutura fonológica
das palavras; e ela aprende a invenção: a representação de uma dessas unidades por
uma forma visual específica (SOARES, 2016, p. 191 - grifos da autora).

A grande questão controversa, ao que se pesquisou e se praticou no Brasil em termos de alfabetização anterior à PNA, reside no fato de tentar "zerar o passado" (BUNZEN, 2019) com o discurso do novo nos moldes do ensino explícito e fonêmico. Há, pois, a desconsideração de pesquisas científicas sérias de naturezas bibliográficas e experimentais sobre métodos de alfabetização e sobre a consciência fonológica. Pesquisas gestadas há mais de duas décadas por pesquisadores de renome em alfabetização, tais como Arthur Gomes de Morais e Magda Soares, Maria do Rosário Longo Mortatti, entre outros.

O cenário que se levanta propõe a alfabetização "baseada em evidências científicas" tendo por aporte os pensamentos de linha psicocognitiva de um grupo de trabalho e "convidando renomados pesquisadores da área de alfabetização para apresentarem suas contribuições" (BRASIL, 2019, p. 3).

Como mencionado, a Edição 10 da Revista Brasileira de Alfabetização reuniu ensaios de inúmeros pesquisadores brasileiros a respeito dos limites e controvérsias presentes na PNA. Assim, os autores, dentre outros aspectos, questionam a formação da equipe de colaboradores organizada pelo MEC. Em que pese a presença massiva de psicólogos nacionais e internacionais, a despeito de pesquisadores da educação e da linguística. Segundo Maciel,

[...] Do conjunto de 21 Especialistas colaboradores, 13 são brasileiros, e apenas 1 da área da Educação com formação em Pedagogia. Aqui indago: qual o lugar da educação, do fazer pedagógico, do alfabetizador e do alfabetizando em uma política nacional de alfabetização que traz majoritariamente o viés da psicologia e, dentro dela, a Psicologia 'especialmente da ciência cognitivada da leitura'? Ora, o alfabetizando e o alfabetizador são sujeitos históricos, situados, e o processo de aprendizagem da leitura e da escrita não pode ser restrita a uma única faceta (MACIEL, 2019, p. 58). 
Reforçamos o questionamento da autora a respeito dos saberes construídos na prática dos professores alfabetizadores (PINHEIRO; SANTOS, 2018), conceituados como saberes ordinários (CHARTIER, 2007), que devem ser considerados na proposição e elaboração de políticas públicas de alfabetização.

[...] os professores se servem de um número considerável de 'saberes científicos' em suas salas de aula, mas eles nem sempre têm consciência disso, porque certos saberes já pertencem tanto a suas categorias de pensamento e de sua cultura escolar que eles os utilizam como se fossem realidades naturais (CHARTIER, 2010, p. 13).

São esses saberes ordinários, construídos na prática dos professores alfabetizadores, que se pretende silenciar pelo discurso impositivo da PNA que se diz inovadora e eficaz. A política do silêncio (ORLANDI, 2007) se instaura desde a gênese da PNA ao se desconsiderar o princípio democrático que garantisse uma consulta de especialistas brasileiros sobre os melhores encaminhamentos para os processos de alfabetização no país. Essa constatação se dar por dois motivos: I) por ser instituída via decreto presidencial sem consulta pública às universidades, aos professores da educação básica e à sociedade civil; II) por restringir a colaboração de pedagogos e pesquisadores em educação, privilegiando os psicólogos da ciência cognitiva, em sua maioria vinculados a laboratórios de investigações internacionais.

Vale ressaltar o reforço que o cenário atual ganha quando analisamos os documentos elencados como evidências científicas, tão recorrentemente citados no texto da política em questão, para "impor" o método fônico como caminho mais acertado a ser seguido no ciclo de alfabetização, conforme observado na tabela a seguir:

Tabela 1- Evidências científicas de êxito na alfabetização de instrução fônica na PNA

\begin{tabular}{|c|c|c|c|}
\hline PAÍS & ANO & RELATÓRIO & PROPOSTA \\
\hline EUA & 1967 & $\begin{array}{l}\text { Learning to Read: The } \\
\text { Great Debate }\end{array}$ & $\begin{array}{l}\text { Recomenda abordagem fônica e ensino } \\
\text { explicito. }\end{array}$ \\
\hline EUA & 1998 & $\begin{array}{l}\text { O Preveting Reading } \\
\text { Difficulties in Young } \\
\text { Children }\end{array}$ & $\begin{array}{l}\text { Identifica os elementos essenciais para } \\
\text { ensinar a ler e a escrever com qualidade. }\end{array}$ \\
\hline EUA & 2000 & $\begin{array}{l}\text { Relatório do National } \\
\text { Reading Panel }\end{array}$ & $\begin{array}{l}\text { Identifica os cinco pilares para uma alfabe- } \\
\text { tização de qualidade }\end{array}$ \\
\hline EUA & 2009 & $\begin{array}{l}\text { Relatório Developing } \\
\text { Early Literacy }\end{array}$ & $\begin{array}{l}\text { Elenca a literacia familiar e habilidades } \\
\text { desenvolvidas na pré-escola }\end{array}$ \\
\hline BRA & $\begin{array}{r}2003 / \\
2007\end{array}$ & $\begin{array}{l}\text { Relatório final Alfabeti- } \\
\text { zação Infantil: os novos } \\
\text { caminhos }\end{array}$ & $\begin{array}{l}\text { Conclui que as políticas e práticas alfabe- } \\
\text { tizadoras do país não acompanharam o } \\
\text { progresso científico e metodológico. }\end{array}$ \\
\hline BRA & 2004 & $\begin{array}{l}\text { Relatório final Educação } \\
\text { de Qualidade Começan- } \\
\text { do pelo Começo }\end{array}$ & $\begin{array}{l}\text { Aponta os mesmos componentes essen- } \\
\text { ciais para a alfabetização presentes no } \\
\text { National Reading Panel. }\end{array}$ \\
\hline BRA & 2011 & $\begin{array}{l}\text { Documento Aprendiza- } \\
\text { gem Infantil: uma abor- } \\
\text { dagem da neurociência, } \\
\text { economia e psicologia } \\
\text { cognitiva }\end{array}$ & $\begin{array}{l}\text { Faz referência aos países que mudaram } \\
\text { suas políticas públicas para alfabetização } \\
\text { com base nas evidências científicas mais } \\
\text { recentes, incorporando recomendações de } \\
\text { instrução fônica. }\end{array}$ \\
\hline
\end{tabular}

Fonte: Elaborado pelos autores a partir de Brasil (2019) 
Percebe-se em todos os documentos acima relacionados, nacionais ou internacionais, a forte marca da instrução fônica como orientação/prescrição a ser seguida nas salas de alfabetização, dada a comprovada evidência do método fônico para aprendizagem da escrita do código linguístico, segundo tais investigações.

No que diz respeito às pesquisas citadas na Tabela 1 praticadas no Brasil, necessário se faz estabelecer um paralelo com o que Morais (2019) apresenta sobre o método fônico em salas de alfabetização. A partir de pesquisas experimentais no Estado de Pernambuco, ao longo das últimas três décadas, em salas de alfabetização, Morais (2019) concluiu que a consciência fonêmica, a qual integra a consciência fonológica, não compõe um saber necessariamente construído por crianças com alfabetização consolidada. Segue explicando que, das tarefas de consciência fonológica apresentadas às crianças, as que tiveram menos êxito foram efetivamente as de contagem de fonemas e segmentação oral de palavras em fonemas. Ou seja, a consciência fonêmica não constitui habilidade de extrema relevância para que as crianças se alfabetizem. De certa forma, o pensamento de Morais (2019) desconstrói a ideia construtivista de que a criança desenvolve a consciência fonológica no processo de alfabetização, em que pesem as reflexões orais que pratica antes da educação formal ou na educação infantil; como também desmitifica o reducionismo de que a faceta linguística é desenvolvida (ou melhor desenvolvida) pelos alfabetizandos expostos ao método fônico, à instrução fonêmica sistemática.

Morais (2019) investigou crianças alfabetizadas pelo método fônico, através das Cartilhas do Alfa e Beto ${ }^{7}$ para reiterar suas considerações acerca da pouca desenvoltura na segmentação oral de fonemas. Segundo o autor (2019), em se tratando dos alunos alfabetizados com o método fônico, os resultados impressionam bastante, pois esses "fracassaram nas tarefas que mediam habilidades de consciência fonêmica, algumas treinadas pelo próprio material didático a que estavam expostos" (p. 111-112).

Dessa forma, as evidências científicas que se estruturaram no Brasil, para além daquelas apontadas pela PNA, não negam, em partes, a potencialidade do método fônico para o desenvolvimento de determinadas habilidades metalinguísticas. Mas, também não descartam os caminhos diversos que o construtivismo propõe, que a prática docente constrói (os saberes ordinários) e o que o aluno conhece em termos de linguagem (aspectos da consciência fonológica) anterior à educação formal.

Corroborando com as conclusões de Morais (2019), dois estudos estrangeiros, apresentados no Congresso Brasileiro de Alfabetização (Conbalf 2019), sugerem a ineficácia da prescrição de apenas um método para a alfabetização, conforme a tabela que segue:

7 O programa de alfabetização Alfa e Beto foi criado em 2006, sendo produzido por uma organização não governamental sem fins econômicos e destinava-se à alfabetização de crianças das primeiras séries do Ensino Fundamental, podendo, também, ser usado com êxito para alfabetização de crianças que apresentaram defasagem de aprendizagem da leitura e da escrita. A partir do método fônico, as cartilhas destinadas aos alunos eram defendidas sob o discurso de correção do fluxo escolar e a defasagem idade-série no ensino fundamental. Vale salientar que as cartilhas do referido programa não passavam pelo crivo do Programa Nacional do Livro didático (PNLD). A esse respeito, ver Barbosa (2013). 
Tabela 2 - outras evidências contrárias à PNA

\begin{tabular}{|l|l|}
\hline \multicolumn{1}{|c|}{${\text { Uta } \text { Papen }^{8}}^{8}$} & \multicolumn{1}{c|}{ Margarida Alves Martins $^{9}$} \\
\hline $\begin{array}{l}\text { Pesquisa sobre as políticas do Reino Unido, } \\
\text { dos Estados Unidos e da Austrália que prio- } \\
\text { rizam a instrução fônica e investigam a práti- } \\
\text { ca de professores. }\end{array}$ & $\begin{array}{l}\text { Pesquisa realizada em Portugal, de caráter } \\
\text { comparativo e com controle de algumas } \\
\text { variáveis. }\end{array}$ \\
\hline $\begin{array}{l}\text { Concluiu que os professores fazem mais do } \\
\text { que foi prescrito para alfabetizar as crianças. }\end{array}$ & $\begin{array}{l}\text { Concluiu que nem alfabetização baseada } \\
\text { apenas no uso da escrita nem apenas em } \\
\text { instrução fônica obtiveram bons resulta- } \\
\text { dos. }\end{array}$ \\
\hline
\end{tabular}

Fonte: Elaborado pelos autores a partir dos Anais do Conbalf (2019)

As conclusões de Papen e Martins (FRADE, 2019) desmistificam a polarização de método único de alfabetização, ratificando o que Soares (2016) discute sobre 'a questão dos métodos'. Concordamos a afirmar: não é o método; são os métodos que em simbiose, ante à alfabetização, dão conta da aprendizagem da leitura e da escrita. Pois, diferente da PNA, defende-se a representação da cadeia sonora da fala como sistema notacional (MORAES, 2005; SOARES, 2016), visto que os grafemas notam (representam) os fonemas em um sistema alfabético de escrita. $\mathrm{O}$ código, o codificar, o decodificar sugerem mecanização desse sistema de representação, pois ao se falar de consciência fonológica e de sistema notacional, as pesquisas brasileiras dão conta da reflexão necessária sobre a língua escrita no processo de aquisição pelas crianças no ciclo de alfabetização.

Morais (2005) e Soares (2018) atentam para o termo Sistema Notacional em detrimento de Código Linguístico. Os autores salientam que código, codificar e decodificar são termos inadequados em se tratando de língua e alfabetização, visto que a língua não é um código e alfabetizar-se tampouco é apenas codificar ou decodificar a língua oral e escrita, respectivamente: "[...] um código é, em seu sentido próprio, um sistema que substitui (como o código Morse, a escrita em Braille) ou esconde (como códigos de guerra, criados para garantir a segurança de comunicações) os signos de um outro sistema já existente [...]" (SOARES, 2018, p. 46).

A retomada dos termos 'código', 'codificar' e 'decodificar' configura mais um reducionismo defendido pela PNA que leva ao reducionismo da alfabetização ao "ensino das habilidades de leitura e escrita em um sistema alfabético" (BRASIL, 2019, p. 18). É nessa perspectiva que o emaranhado de reducionismos que integram a PNA acerca de alfabetização, de sistema alfabético, de princípio alfabético e de código linguístico, cerceia o termo letramento do cenário educacional brasileiro, impondo o termo literacia. Se comparado ao texto da Base

8 Pesquisadora em alfabetização e antropóloga social que estuda o papel da linguagem escrita no cotidiano, nos contextos institucionais e na educação. Considera a alfabetização não apenas uma habilidade cognitiva, mas uma prática social e cultural. Em suas pesquisas, leva em conta o papel do poder no que diz respeito à alfabetização e à educação para a alfabetização, examinando como as políticas e as pesquisas têm impacto no ensino e na aprendizagem.

9 Doutora em Ciências da Educação pela Universidade René Descartes, Paris V e em Psicologia Pedagógica pela Universidade de Coimbra. É professora de Psicologia da Educação no ISPA-Instituto Universitário, Lisboa, Portugal, em cursos de mestrado e doutorado. Dirige o Centro de Investigação em Educação (CIE-ISPA), desenvolvendo investigação sobre os processos de aprendizagem da escrita e da leitura. 
Nacional Comum Curricular (BNCC) que o utiliza 48 vezes, a PNA sequer o menciona e, invés disso, faz uso maciço do termo literacia, por não menos de, 73 vezes.

Há, por parte da PNA, a clara intenção de silenciar (ORLANDI, 2007) o termo letramento das reflexões e iniciativas políticas para a alfabetização, pela leitura equivocada das contribuições de concepções e métodos de alfabetização adotados no país. Ingênuo seria pensar nesse silenciamento isento de neutralidade, pois o conceito de literacia, defendido na PNA, surge acompanhado de uma visão unilateral, reducionista, disciplinar e escolarizada dos processos de aprendizagem das práticas sociais, dos gêneros e dos usos da leitura e da escrita (BUNZEN, 2019), conforme discutiremos na próxima seção.

Dentre os reducionismos elencados, passamos a enfocar mais detalhadamente o apagamento do termo letramento para dar espaço ao termo que emerge: literacia. Termo que, numa tradução às avessas, descarta o trabalho com a língua em uso social, e faz "tábula rasa do que se vem pesquisando sobre as especificidades e interrelações entre "letramento" e "alfabetização" e sobre a singularidade que assumem em nosso país, diferentemente do que ocorre nos países ricos de língua inglesa" (MOARAIS, 2019b, p. 69-70).

\section{ALFABETIZAÇÃO, LETRAMENTO E LITERACIA: UM PROCESSO DE SILENCIAMENTO}

O processo histórico que se deu a partir da construção dos conceitos de alfabetização, letramento no Brasil e literacia permite afirmar o quanto esse percurso não está voltado diretamente para a preocupação sobre o analfabetismo brasileiro e seus baixos índices de proficiência em leitura e escrita segundo os resultados da Avaliação Nacional da Alfabetização (ANA), no ano de 2016. Esse processo enfatiza, principalmente, aspectos políticos e econômicos que perpetuam considerações acerca dos termos que refletem, sobretudo, a relação da educação com o que se considera a aquisição da língua escrita. Para isso, é necessário ter claro como esses conceitos foram construídos e percebidos ao longo da história da alfabetização.

A alfabetização "refere-se à aquisição da escrita enquanto aprendizagem de uma habilidade para a leitura, escrita e as chamadas práticas de linguagem" (TFOUNI, 2005, p. 9). Para Soares (2003), a alfabetização também pode ser entendida como uma aprendizagem de uma técnica. Segundo a autora (2016), em "Alfabetização: a questão dos métodos", quando no processo de alfabetização o objeto de aprendizagem inicial da língua é o sistema alfabético-ortográfico, com foco explícito no desenvolvimento das competências de notar/representar de forma escrita a cadeia sonora da fala (ler e escrever), estamos a privilegiar a faceta linguística (SOARES, 2016). Essa técnica diz respeito também à aprendizagem motora de como se deve pegar no lápis, e de que para escrever o aluno deve seguir uma orientação espacial, entendendo que letras são escritas da esquerda para a direita e de cima para baixo, além de compreender que a formação das palavras acontece de acordo com o uso de uma sequência determinada de letras (SOARES, 2003).

A alfabetização entendida como a aprendizagem de uma técnica pressupõe o ensino explícito e formal do sistema alfabético-ortográfico, de modo que sejam enfatizados aspectos que evidenciam a memorização e a repetição, mas não no mesmo sentido em que foram atribuídos os métodos tradicionais de alfabetização (MORTATTI, 2006).

No documento oficial da PNA (BRASIL, 2019), a alfabetização é compreendida como o ensino da habilidade de compreensão do código linguístico, com ênfase nas habilidades de 
codificar/decodificar. Para isso, a PNA prescreve a aplicação de seis componentes para sua efetivação, evidenciando-se a relação com o caráter mais explícito da apropriação da língua escrita.

Figura 1 - Componentes essenciais para a alfabetização

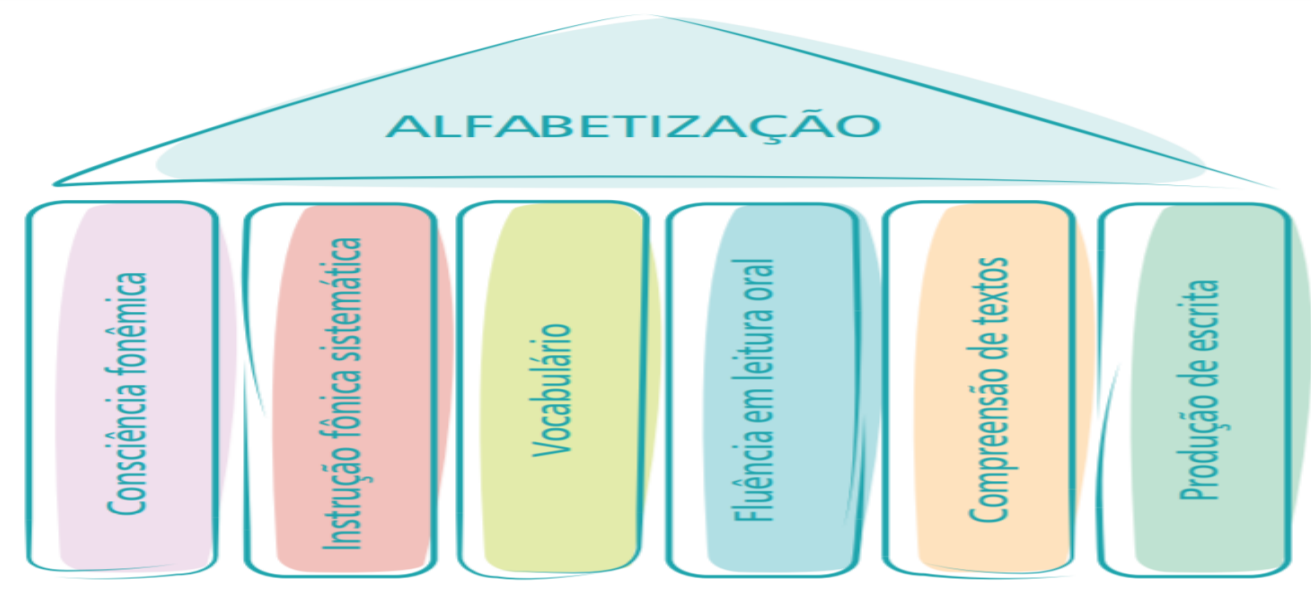

Fonte: BRASIL (2019, p. 33)

Os componentes que integram a alfabetização proposta na PNA resultam do que o grupo de trabalho constituído para a sua elaboração da PNA considera como evidências científicas mais atuais, tendo por base os relatórios nacionais e internacionais, anteriormente apresentados (Tabela 1), que propõem cinco componentes: consciência fonêmica, instrução fônica sistemática, fluência em leitura oral, desenvolvimento de vocabulário e compreensão de textos. Todavia, a PNA lança mão do discurso de outras pesquisas mais recentes para introduzir o sexto componente.

[...] Pesquisas mais recentes, no entanto, recomendam a inserção de outro componente, a produção de escrita, e assim se obtêm os seis componentes propostos pela PNA, nos quais se devem apoiar os bons currículos e as boas práticas de alfabetização baseada em evidências (BRASIL, 2019, p. 32 - grifo nosso).

Em contextos que considerem o letramento, a produção de escrita apontada pela PNA seria, pois, a produção dos mais variados gêneros do discurso, considerando não apenas a materialidade linguística, a escrita de palavras, frases e pequenos textos, mas, da língua em uso social. É nesse sentido que o termo produção de escrita em substituição à produção de gêneros discursivos corrobora para efetivar e validar o uso do termo literacia.

Ao expor sobre alfabetização, é necessário ampliar as discussões sobre o letramento, tendo em vista que esse processo é essencial durante a aquisição da língua escrita. Soares (2014) afirma que ambos são indissociáveis, mas possuem diferenças entre si: o termo letramento envolve as práticas sociais de leitura e escrita (SOARES, 2003). No entanto, a entrada da criança no mundo letrado ocorre bem antes da alfabetização, por meio do seu contato com práticas de leitura e escrita na sociedade, enquanto que a alfabetização se realiza mediante contextos formais de ensino, isto é, de ensino explícito da língua escrita.

Por letramento, considera-se as diferentes práticas sociais da leitura e da escrita (SOARES, 2003). Emergem ainda, no contexto atual, outras reflexões inerentes ao entendimento da polissemia do conceito de letramento que se refere aos usos, funções e valores sociocultu- 
rais da escrita, do texto literário, do conhecimento científico e matemático, da interpretação de imagens, sons e signos semióticos, provocados ou não pela eminencia dos usos das ferramentas digitais, entre outros. A imersão em contextos de letramento possibilita as interações e diálogos com a cultura letrada (MORAIS, 2014), ainda que a criança não domine o sistema de escrita alfabética, realiza leituras logográficas ${ }^{10}$ (SOARES, 2016).

O letramento envolve práticas de leitura e escrita de/por gêneros discursivos (BAKHTIN, 2003). Assim, no contexto de letramento, o trabalho com gêneros discursivos deve desenvolver no aluno a sua competência linguística. Com esse entendimento, assumir a perspectiva pedagógica do letramento nos contextos de aprendizagem da língua escrita implicaria desenvolver nos alunos competências linguísticas favoráveis à participação efetiva e competente nas práticas sociais que permeiam os usos sociais da língua escrita na sociedade.

O letramento, por outro lado, "[...] não contempla, portanto, todas as atividades de leitura e de escrita que são determinadas por necessidades e fins meramente pessoais [...], como se o indivíduo, como ser letrado, não tivesse outra dimensão do que a social" (MORAIS, 2014, p. 13). O letramento não se volta para a aprendizagem do sistema alfabético-ortográfico, no entanto, compreende-se a importância do desenvolvimento do estado ou condição de se fazer uso da leitura e da escrita em diferentes práticas sociais (SOARES, 2003).

Diante das discussões que tratam a PNA, a mudança do termo letramento para literacia, referenciada anteriormente, não significa apenas uma questão de sinônimo, mas, de concepções ideológicas sobre a aprendizagem da leitura e da escrita. Literacia é definida como "o conjunto de conhecimentos, habilidades e atitudes relacionados à leitura e à escrita, bem como sua prática produtiva" (BRASIL, 2019, p. 21). Segundo Morais (2013, p.4), um dos consultores internacionais da PNA, o termo "literacia", "importado da literatura anglo-saxônica (literacy), é utilizado [...] por ter um sentido mais preciso e menos à exploração ideológica do que o termo letramento".

O termo literacia, para Morais (2014), pode ser entendido sob dois sentidos: I) como conjunto de habilidades de leitura e escrita; II) como uma prática produtiva das habilidades de leitura e escrita. Para o autor, em Criar Leitores: para professores e educadores,

\begin{abstract}
Também convém ter em conta que literacia se distingue de alfabetização. Há formas de literacia não alfabética - é o caso de quem sabe ler e escrever em um sistema não alfabético de escrita. Além disso, é costume considerar-se que alguém é alfabetizado mesmo quando só é capaz de compreender e escrever textos de pouca complexidade e não utiliza processos automáticos de identificação das palavras escritas e de ativação das suas formas ortográficas. Ora, um alto nível de literacia alfabética supõe a utilização desses processos e a capacidade de ler e escrever textos muito complexos (MORAIS, 2013, p. 4 - grifo do autor).
\end{abstract}

Com base nesse entendimento sobre o termo literacia, percebe-se as influências às quais o documento da PNA teve por referência. No entanto, nenhuma das colocações desmente a proposição reducionista que o termo possui em comparação ao letramento (SOARES, 2003). A PNA apresenta três diferentes níveis de literacia: básica, intermediária e disciplinar, ilustradas no documento conforme a Figura 2.

10 Entende-se por leitura logográfica o reconhecimento de escritas familiares à criança. Daí, depreende-se o motivo de a criança, mesmo sem saber ler, reconhecer palavras escritas que se impregnam recorrentemente em seu cotidiano, como Coca-Cola, McDonald's, Danoninho, Pipoca Boni (alimento comum às crianças do agreste alagoano), por exemplo. 


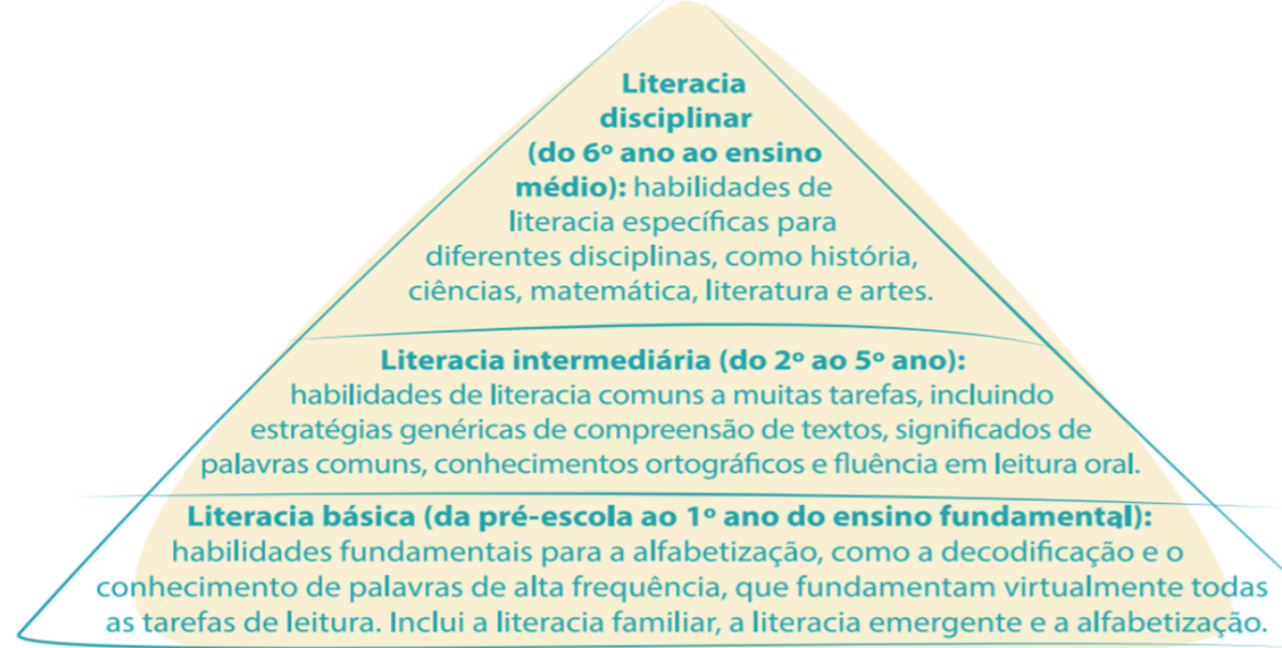

Fonte: BRASIL $(2019$, p. 21)

A literacia básica compreende as habilidades iniciais ao qual envolvem a apropriação da língua escrita incluindo os conceitos de literacia familiar e emergente. A literacia intermediária envolve habilidades mais difíceis, principalmente com relação à fluência da leitura; é a partir desse momento que se percebe maior compreensão dos textos. E por último, a literacia disciplinar, a qual diz respeito às habilidades dos diferentes componentes curriculares das disciplinas, tais como: ciências, história, geografia (BRASIL, 2019).

Morais (2014) amplia o conceito sobre literacia explicitando os seus quatro tipos: pragmática, de divertimento, de conhecimento e estética. Mesmo com essa amplitude, o caráter sobre a literacia, principalmente no contexto escolar, permanece em um reducionismo severo, principalmente por ignorar os aspectos sociais das práticas de letramento (SOARES, 2014). Dessa forma, é preciso ter claro o posicionamento político e ideológico no qual o termo literacia se apresenta, de modo que as relações dialógicas e as interações sociais (VOLÓCHINOV, 2017) não sejam reduzidas a uma percepção escolar, mas efetivamente social.

Dado o exposto, embora o termo letramento seja reconhecido no Brasil, por lhe dar identidade, por ser termo próprio gestado na década de 1980, que ganhou amplitude e se consolidou em nosso cenário educacional nas décadas seguintes para referenciar as práticas sociais de uso da língua, o problema não está relacionado ao uso dos termos - letramento ou literacia, com a substituição, mas com os significados e concepções que embasam o uso do novo conceito que traduz equívocos, reducionismos e retrocesso (BUNZEN, 2019).

Concordamos com Gabriel (2017) em sua assertiva que alfabetização, letramento e literacia não podem ser entendidos como constructos teóricos excludentes, não competem entre si, mas também não se confundem (GABRIEL, 2017). Reiteramos, portanto, que o silenciamento (ORLANDI, 2007) do letramento configura uma tentativa de 'zerar o passado' (BUNZEN, 2019), visto que as escolhas teórico-metodológicas presentes no documento da PNA revelam o não reconhecimento das contribuições sobre alfabetização e letramento, bem como usa aproximações e especificidades. 


\title{
CONSIDERAÇÕES FINAIS
}

Neste artigo, objetivamos refletir acerca dos discursos que integram a Política Nacional de Alfabetização e que mobilizaram os rompimentos com as contribuições das pesquisas nacionais sobre a especificidade e as práticas acerca da alfabetização no Brasil, conjecturando reducionismos conceituais e metodológicos para o silenciamento do conceito de letramento.

Nesse sentido, discutimos sobre aspectos gerais da PNA que refletem reducionismos para a alfabetização no Brasil, tendo em vista o que esse documento elenca como evidências científicas na tentativa de legitimar o método fônico no processo de aprendizagem da língua escrita. Na continuidade discursiva abordamos mais especificamente o conceito de literacia sobreposto ao termo letramento, numa tentativa não neutra de silenciá-lo, configurando-se a desconsideração de pesquisas consolidadas sobre alfabetização no Brasil sobre letramento.

Ao analisar o documento oficial da PNA, compreendemos que, embora apresente o discurso de preocupação com o desempenho nas proficiências em leitura e em escrita, há a aparente preocupação em torno dos resultados das avaliações de larga escala (ANA e PISA). Mesmo a intenção sendo essa, a PNA propõem reducionismos metodológicos e conceituais sobre os caminhos a serem trilhados pela alfabetização enquanto adoção de um método explícito e direcionado à orientação fônica, dando pouca ênfase para ao caráter social da escrita da língua, ao letramento. Logo, o reducionismo mais evidente da referida política centra-se no apagamento do termo e da concepção de letramento na proposição de uma alfabetização vista, tão somente, como o ensino das habilidades de leitura e de escrita em tom de codificação e decodificação, dando lugar ao termo literacia.

Por fim, esse movimentum atual de silenciamento do termo letramento, substituindo-o pelo conceito de literacia, revela uma política ideologizada/ideologizante e de direita para a alfabetização em um processo historicamente complexo no Brasil. Evidencia-se, assim, as permanências de marcas históricas da descontinuidade das políticas públicas nacionais, considerando que vivemos, nas últimas décadas, políticas de governos em detrimento de políticas de Estado. É nestes moldes que se constata tal silenciamento como um posicionamento não neutro.

\section{NATIONAL LITERACY POLICY: THE FOCUS IN LITERACY AND THE SILENCING OF SOCIAL LITERACY}

\begin{abstract}
This paper presents the intercrossing of the National Literacy Policy's discourses and stimulates the understanding about ruptures of the contributions of national researches on the specificity of the alphabetization and social literacy in Brazil. For this, we carried out a documentary study of the National Literacy Policy, in that corpus was analyzed based on the content analysis technique in Bardin (2009) and discussed from Morais (2005, 2012; 2019; 2019a), Soares (2003 ; 2014; 2016), Bakhtin (2003; 2019), Mortatti (2006), Orlandi (2007). The results demonstrate conceptual and methodological reductions in the literacy process that reinforces scientific evidence about the phonic teaching method and, through the allusion to literacy practices, imposes the silencing of the term social literacy, which goes against more than 20 years of consolidated researches on alphabetization and social literacy in this country.
\end{abstract}

KEYWORDS: National Literacy Policy. Social literacy. Literacy.

\section{REFERENNCIAS}

BAKHTIN, Mikhail. Estética da criação verbal. 4. ed. São Paulo: Martins Fontes, 2003. 
O homem ao espelho: apontamentos dos anos 1940. São Carlos: Pedro e João Editores, 2019. BARBOSA, Jamile de Oliveira. A concepção da alfabetização no Programa Alfa e Beto. Trabalho de Conclusão de Curso (Licenciatura em Pedagogia) - Universidade Federal de Sergipe, São Cristóvão, 2013.

BARDIN, L. Análise de Conteúdo. Lisboa, Portugal; Edições 70, LDA, 2009.

BRASIL. Ministério da Educação. Secretaria de Alfabetização. Política Nacional de Alfabetização. Brasília: MEC, SEALF, 2019.

. Base Nacional Comum Curricular. Brasília: MEC, 2017. Disponível em: <http:// basenacionalcomum.mec.gov.br/images/BNC C_20dez_site.pdf>. Acesso em: 28 mar. 2020.

. Ministério da Educação. Planejando a Próxima Década. Conhecendo as 20 Metas do Plano Nacional de Educação. Ministério da Educação/Secretaria de Articulação com os Sistemas de Ensino (MEC/Sase): Brasília, DF., 2014.

BUNZEN, Clecio. Um breve decálago sobre o conceito de 'literacia' na Política Nacional de Alfabetização (PNA, 2019). In: Revista Brasileira de Alfabetização [Recurso eletrônico]/Associação Brasileira de Alfabetização. V. 1, n. 10 (jul./dez. 2019) - Belo Horizonte: ABAlf, 2019 - Edição Especial, p. 44-51.

CELLARD, A. A análise documental. In: POUPART, J. et al. A pesquisa qualitativa: enfoques epistemológicos e metodológicos. Petrópolis, Vozes, 2008.

CHARTIER, Anne-Marie. Práticas de leitura e escrita: história e atualidade. Belo Horizonte: Autêntica, 2007.

. Ensinar a ler e escrever, entre teoria e prática. Palestra apresentada na V Semana da Educação, da Fundação Victor Civita. São Paulo, 20 de outubro de 2010. Disponível em: <https://novaescola. org.br/conteudo/1635/palestra -de-anne-marie-chartier-na-semana-daeducacao-2010> Acesso em: 28 mar. 2020.

FRADE, Isabel Cristina Alves da Silva. Um paradigma científico e evidências a ele relacionadas resolveriam os problemas da alfabetização brasileira? In: Revista Brasileira de Alfabetização [Recurso eletrônico]/Associação Brasileira de Alfabetização. V. 1, n. 10 (jul./dez. 2019) - Belo Horizonte: ABAlf, 2019 - Edição Especial, p. 15-25.

GABRIEL, Rosângela. (2017). Letramento, Alfabetização e Literacia: um olhar a partir da ciência da leitura. Revista Prâksis. 2. 76. 10.25112/rpr.v2i0.1277.

MACIEL, Francisca Isabel Pereira. Onde estão as pesquisas sobre alfabetização no Brasil? . In: Revista Brasileira de Alfabetização [Recurso eletrônico]/Associação Brasileira de Alfabetização. V. 1, n. 10 (jul./dez. 2019) - Belo Horizonte: ABAlf, 2019 - Edição Especial, p. 58-62.

MORAIS, Artur Gomes de. Se a escrita alfabética é um sistema notacional (e não um código), que implicações isso tem para a alfabetização? In: MORAIS, Artur Gomes de; ALBUQUERQUE, Eliana Borges Correia de; LEAL, Telma Ferraz (Orgs.). Alfabetização: a apropriação do sistema de escrita alfabética. Belo Horizonte: Autêntica, 2005, p. 29-46.

. Consciência fonológica na educação infantil e no ciclo de alfabetização. 1. ed. Belo Horizonte: Autêntica Editora, 2019.

. Análise crítica da PNA (Política Nacional de Alfabetização) imposta pelo MEC através de decreto em 2019. In: Revista Brasileira de Alfabetização [Recurso eletrônico]/Associação Brasileira de Alfabetização. V. 1, n. 10 (jul./dez. 2019) - Belo Horizonte: ABAlf, 2019a - Edição Especial, p. 66-75.

Sistema de escrita alfabética. São Paulo: Editora Melhoramentos, 2012.

MORAIS, José. Alfabetizar para a democracia. Porto Alegre: Penso, 2014.

. Criar Leitores: para professores e educadores. São Paulo: Manole, 2013.

MORTATTI, Maria Rosário Longo. História dos Métodos de Alfabetização no Brasil. Ministério da Educação (MEC), 2006. Disponível em: <http://portal.mec.gov.br/seb/arquivos/pdf/Ensfund/ alf_mortattihisttextalfbbr.pdf $>$ Acesso em: 27 mar. 2020. 
ORLANDI, Eni Puccinelli. As formas do silêncio: no movimento dos sentidos. $6^{\mathrm{a}}$ ed. Campinas: Editora da Unicamp, 2007.

PINHEIRO, Viviane Caline de Souza; SANTOS, Adriana Cavalcanti dos. Avaliação Nacional da Alfabetização: proficiência em leitura em Alagoas. Revista Educação e Linguagens, v. 7, p. 34-49, 2018.

SANTOS, J. PINHEIRO, V. SANTOS, A. C. Matriz de referência de língua portuguesa da avaliação nacional de alfabetização: (des)dobramentos em estratégias didáticas. Revista Humanidades e Inovação v.7, n.1 - 2020.

SOARES, Magda. A Reinvenção da Alfabetização. Revista Presença Pedagógica, Belo Horizonte, v.9, n.52, jul/ago 2003. Disponível em: <http://www.gestaoescolar.diaadia.pr.gov.br/arquivos/File/ programa_aceleracao_estudos/reivencao_alfabetizacao.pdf $>$ Acesso em: 27 mar. 2020.

. Letramento: um tema em três gêneros. $3^{\mathrm{a}}$ ed. Belo Horizonte: Autêntica Editora, 2014.

. Alfabetização: a questão dos métodos. São Paulo: Contexto, 2016.

TFOUNI, Leda Verdiani. Letramento e alfabetização. São Paulo: Cortez, 2005.

VOLÓCHINOV, Valentin. Marxismo e filosofia da linguagem: problemas fundamentais do método sociológico na ciência da linguagem. São Paulo: Editora 34, 2017.

Data submissão: $11 / 05 / 2020$

Data aprovação:10/07/2020 